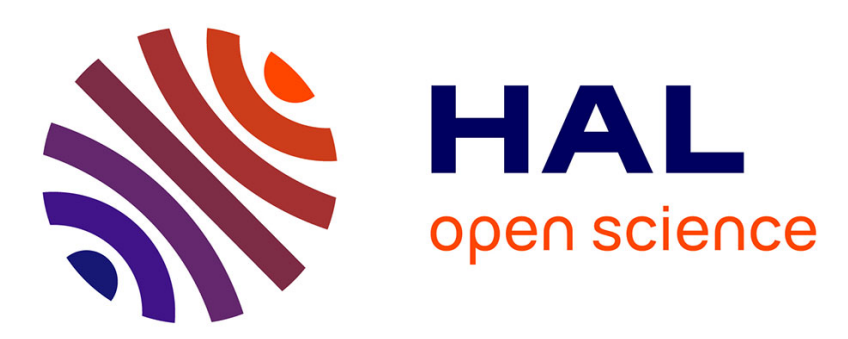

\title{
Comparative numerical studies of projectile impacts on plain and steel-fibre reinforced concrete
}

Ulrika Nyström, Kent Gylltoft

\section{To cite this version:}

Ulrika Nyström, Kent Gylltoft. Comparative numerical studies of projectile impacts on plain and steel-fibre reinforced concrete. International Journal of Impact Engineering, 2010, 38 (2-3), pp.95. 10.1016/j.ijimpeng.2010.10.003 . hal-00757020

\section{HAL Id: hal-00757020 \\ https://hal.science/hal-00757020}

Submitted on 26 Nov 2012

HAL is a multi-disciplinary open access archive for the deposit and dissemination of scientific research documents, whether they are published or not. The documents may come from teaching and research institutions in France or abroad, or from public or private research centers.
L'archive ouverte pluridisciplinaire HAL, est destinée au dépôt et à la diffusion de documents scientifiques de niveau recherche, publiés ou non, émanant des établissements d'enseignement et de recherche français ou étrangers, des laboratoires publics ou privés. 


\section{Accepted Manuscript}

Title: Comparative numerical studies of projectile impacts on plain and steel-fibre reinforced concrete

Authors: Ulrika Nyström, Kent Gylltoft

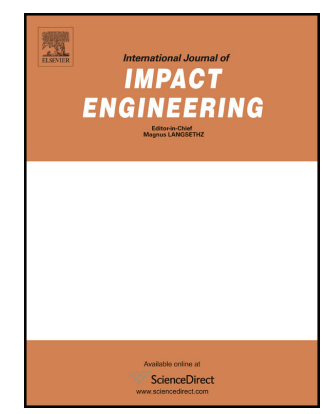

PII:

S0734-743X(10)00149-1

DOI:

10.1016/j.ijimpeng.2010.10.003

Reference: IE 1918

To appear in: International Journal of Impact Engineering

Received Date: 14 July 2008

Revised Date: 7 June 2010

Accepted Date: 2 October 2010

Please cite this article as: Nyström U, Gylltoft K. Comparative numerical studies of projectile impacts on plain and steel-fibre reinforced concrete, International Journal of Impact Engineering (2010), doi: 10.1016/j.jijmeng.2010.10.003

This is a PDF file of an unedited manuscript that has been accepted for publication. As a service to our customers we are providing this early version of the manuscript. The manuscript will undergo copyediting, typesetting, and review of the resulting proof before it is published in its final form. Please note that during the production process errors may be discovered which could affect the content, and all legal disclaimers that apply to the journal pertain. 


\title{
Comparative numerical studies of projectile impacts on plain and steel-fibre reinforced concrete
}

\author{
Ulrika Nyström*, Kent Gylltoft \\ Department of Civil and Environmental Engineering, Structural Engineering, Concrete Structures, \\ Chalmers University of Technology, SE-412 96 Göteborg, Sweden \\ (*ulrika.nystrom@chalmers.se)
}

\begin{abstract}
The enhanced energy absorption characteristics of fibre-reinforced concrete, compared to plain concrete, has in experimentally studies been shown to improve the projectile resistance and motivate its increased usage in protective structures. However, the high cost of undertaking experiments and the high parameter variation and dependency of the experimental setups and results, respectively, make it difficult to draw generic conclusions of how the addition and increased amount of fibres affects the local damage caused by projectile impact, which motivates the use of numerical simulations to study this. The numerical hydrocode AUTODYN was used in a qualitative study of how the addition of different amounts of fibres, modelled as different post-crack relations, influence the depth of penetration and crater formation on the front and rear face of a concrete target. Fibres added to the concrete mix had a minor influence on the depth of penetration while the crater size on both front and rear faces of the target decreases. The crack propagation beyond the crater on the front face was also reduced when fibres were added to the concrete. An increased amount of fibres in the concrete showed no effect on the size of the front-face crater, but led to further decreased size of the crater on the rear face of the concrete cylinder. It is concluded that the scabbing crater can be reduced in size and prevented by usage of fibre-reinforced concrete even if the depth of penetration is only slightly less than to penetration depth in plain concrete.
\end{abstract}

Keywords: Numerical simulation, Projectile impact, Steel-fibre reinforced concrete, Penetration

\section{Introduction}

A projectile impact may cause local and global damage to a concrete structure. Global damage consists of flexural deformations, which, unlike local damage, may cause structural failure. Local damage may 
cause spalling and crushing of concrete on the front face and scabbing on the rear face of the target, together with projectile penetration into the target or even full penetration (i.e. perforation) of the target [1,2]. Different variables have been proposed to measure local damage, such as depth of penetration, perforation and scabbing thickness or ballistic limit (i.e. the minimum velocity at which the projectile penetrates the target) in plain or reinforced concrete [2].

Researchers have experimentally studied the behaviour of fibre-reinforced concrete under impact loading and observed a significant increase in the overall resistance to local damage when compared to plain concrete [3-11]. However, the structural behaviours of targets subjected to impact are complicated, depending on material factors as well as test-condition factors [6], which vary between the reported experiments and therefore make it difficult to draw generic conclusions of the effect of fibres and how it changes with different amounts of fibres in the concrete.

The local damage parameters in concrete are often estimated by using empirical, semi-empirical or purely analytical equations. Even if these equations have the ability to predict local damage variables with high reliability under conditions similar to those used in developing the equations, they may not be generic enough to predict the variables under slightly different circumstances [1,2,12-17].

Another way to estimate the damage caused by projectile impact is to use hydrocode simulations. This is growing more common as computing becomes faster, cheaper and more powerful, and as the material models become more reliable. These computer codes are representations of the conservation laws for a continuum using different numerical schemes. Using a numerical-simulation tool is motivated by the high cost of undertaking impact tests and the ease of changing material properties. Hence, it is possible to study the influence of different parameters, such as fracture energy, which depends on the volume fraction of added fibres, and different impact conditions. However, in order to make simulations an effective tool in this kind of studies the fibre-reinforced concrete has to be homogenized and modelled as one material instead of modelling each of the discrete fibre and its bond to the surrounding concrete. Numerical simulations were performed by Tham [15] and Hansson [18], among others, using AUTODYN-2D and AUTODYN-3D [19], to study the perforation of concrete targets by steel projectiles. They concluded that the simulated local damage showed good agreement with experimental data.

The objective of this paper is to improve the understanding of, and to qualitatively study, how the addition and increased amount of fibres in concrete influences the depth of penetration and crater 
formation on the front and rear faces of steel-confined concrete cylinders of different lengths. This is done by using numerical simulations where the effect of fibres is limited to an improved post-crack behaviour in a macroscopic model for the concrete. This is a substudy within a research project whose long-term aim is to study the behaviour of concrete structures subjected to blast and fragment impacts, and the synergy effect of these loads. The research project is a collaboration between Chalmers University of Technology and the Swedish Rescue Services Agency. In earlier studies within the project, the effect of blast waves in reinforced-concrete structures, fragment impacts on plain concrete, design with regard to explosions and reinforced concrete subjected to projectile impact were studied by Johansson [20], Leppänen [21] and Nyström [22,23], respectively.

\section{Material properties of plain and steel-fibre-reinforced concrete}

\subsection{Plain concrete}

A uni-axial stress-strain relationship, as shown in Fig. 1a, is often used to characterize the static material behaviour of concrete. The ultimate tensile strength, $f_{t}$, for normal-strength concrete is less than one tenth of the ultimate compressive strength, $f_{c}$, and an increasing value of the compressive strength leads to a decreasing ratio between tensile and compressive strengths; Fig. $1 \mathrm{~b}$.

Moreover, after failure initiation in uni-axial tension, stresses can be transferred over the crack. The crack can in a more literal way be described as a process zone consisting of a system of discontinuous micro-cracks. When the propagating micro-cracks have formed a continuous crack, the critical crack opening, $w_{c}$, is reached and no more stresses can be transferred over the crack. The softening behaviour is often shown as a relation between the stress and the crack opening, where the area under the curve represents the fracture energy, $G_{F}$. To simplify, the softening branch is often idealised to a bi-linear (e.g. Gylltoft [25]) or power function (e.g. Hordijk-Reinhard expression, [26]) as shown in Fig. 2.

In building structures the state of stress is multi-axial, and in the case of impact loading, the lateral stresses may be very high. Compressed concrete also subjected to lateral confinement has increased strength and stiffness compared with unconfined concrete. Furthermore, confinement of concrete results in increased ductility.

The conventional stress-strain curve (e.g. in Fig. 1a) for uniaxial loading does not adequately represent the state of stress and strain to which a material is subjected under shock loading since the 
porosity of concrete results in a nonlinear relation between the hydrostatic pressure and the density of the material. Pressures above the so-called Hugoniot elastic limit (HEL) leads to damage of the concrete matrix due to compression, i.e. collapse of pores, and gives plastic compaction of the concrete. For pressures resulting in total collapse of the pore-structure in the concrete the material behaves as a granular and the relation between the hydrostatic pressure and the density becomes linear again. A so-called equation of state (EOS) is used to mathematically describe the behaviour of the material for all possible states of stress. Contrary to gases, where the ideal gas law constitutes the EOS, a general EOS for solid materials cannot be derived. Instead the EOS for solids are based on the experimentally determined Hugoniot curve. A schematic EOS for concrete is shown in Fig. 3, where it can be seen how the relation between the hydrostatic pressure, $p$, and the density, $\rho$ varies. In this figure $p_{\text {crush }}$ represents the HEL, $\rho_{0}$ the initial density of concrete, and $\rho_{s}$ the density of fully compacted concrete after unloading.

Impact loading, such as fragment and missile impact, causes high strain rates in the target material, and since most materials are somewhat strain-rate-dependent, the strength of the target material will increase compared to the static strength. Concrete is also a strain-rate-sensitive material where a significantly increased strength can be seen for relatively low strain rates. The ultimate uni-axial compressive strength for normal-strength concrete may be more than doubled and, according to Bischoff [27] and Ross et al. [28], the ultimate uni-axial tensile strength can increase by a factor 5 to 7 at very high strain rates.

It has earlier been unclear whether the fracture energy is strain-rate-dependent or not, mostly due to the lack of reliable experimental test procedures for which the fracture energy for high strain rates could be measured. Weerheijm [29] concluded that the fracture energy is strain-rate-independent since experiments showed relatively constant fracture energy up to strain rates of $23 \mathrm{~s}^{-1}$, but more recent studies ([30-32]) indicate that also the fracture energy is strain-rate-dependent. Schuler [30] has proposed a relation between the dynamic increase factor for the fracture energy for concrete, defined as the ratio between the dynamic fracture energy and the static fracture energy, and the crack-opening velocity, as shown in Fig. 4.

\subsection{Steel-fibre-reinforced concrete}

The primary effect of adding fibres to concrete is that they improve the post-cracking behaviour and the toughness, i.e. the capacity of transferring stresses after matrix cracking, whereas the modulus of elasticity and the tensile and compressive strengths are not significantly affected as long as a moderate 
dosage $(<1 \%)$ of fibres is used [33]. However, the effect of fibres is highly dependent on the type of fibre used, the size and properties of the fibres, the volume fraction added and the properties of the concrete matrix.

In plain concrete, the shear capacity is explained as aggregate interlock and friction between the shear planes. When adding low and moderate dosages of fibres to the plain concrete, the cracking strength is not affected, but as soon as the matrix cracks the fibres are activated and start to be pulled out, leading to an increased shear-transfer capacity.

As the relation of the stress-crack opening $(\sigma-w)$ curve for steel-fibre reinforced concrete is more or less complex, the relation is often simplified in the same manner as for plain concrete. For practical applications it has been found that the bi-linear relation according to Fig. 5 is often a sufficient approximation. By experiments Löfgren [33] has made phenomenological interpretations of the parameters in the bi-linear $\sigma-w$ relation for steel-fibre reinforced concrete. The decreasing rate of the tensile-stress capacity directly after tensile-failure initiation in the material, parameter $a_{l}$, is essentially governed by the fracture properties of plain concrete, but may be slightly reduced compared to this. The slope of the second branch in the $\sigma-w$ curve, parameter $a_{2}$, is principally related to the fibre length. The critical crack opening $w_{c}$, for which no more stresses can be transferred by the crack, is in the range of $L_{f} / 10$ to $L_{f} / 2$, where $L_{f}$ is the length of the fibre, but poor fibre bond or fibre fracture may lead to a reduced critical crack opening. The value of parameter $b_{2}$ is primarily related to fibre dosage and increases with an increasing fibre-volume fraction.

Even though it is limited there is experimental data to determine the EOS for normal concrete, but for fibre-reinforced concrete the number of relevant experiments are even lower. However, observations from experiments of shock loaded plain and fibre-reinforced concrete together with some free reasoning may give some indications on how the EOS for concrete is affected as steel fibres are added. It has been stated, by e.g. Greulich [34], that steel-fibre-reinforced concrete has the same generic behaviour as plain concrete, which is believed to be true at least for low and moderate dosages of fibres. This may be explained by the fact that the steel fibres do not undergo plastic compaction and therefore their density does not change during shock loading. According to conclusions drawn by Greulich [34], based on experiments of plain concrete presented in Riedel [35] and Landmann [36], the wave velocity in the porous material, which is relevant for determining the inclination of the linear part of the pressure-density 
relation for pressures below the HEL, is higher the higher the initial density of the material is. It is believed that an increased density has the same effect on the wave velocity in the fully compacted material, i.e. an increased density of fully compacted material results in a higher wave velocity. Even though this effect is not believed to be a result of the steel-fibres them self this means that a somewhat stiffer elastic behaviour of the steel-fibre-reinforced concrete may be expected than for normal concrete since steel has a higher density than concrete and thereby both the initial density and the density of the fully compacted material is higher for steel-fibre-reinforced concrete than normal concrete.

\section{Study procedure and analyses}

An experiment performed at the Swedish Defence Research Agency (FOI) in 1998, see [18], was used to validate the numerical model of projectile impact on plain concrete. In the comparative study presented in this paper, where the effect of added steel fibres in the concrete was limited to an improved postcracking behaviour, the numerical model for fibre-reinforced concrete was not validated against measured damage variables from a specific experiment. The numerical results from simulations with fibrereinforced concrete, which are assumed to give the overall behaviour of projectile impact on fibrereinforced concrete compared to plain concrete, were compared to conclusions drawn from experiments described in [3-11]. The procedure is schematically illustrated in Fig. 6.

\subsection{Benchmark experiment}

In the experiment reported by Hansson [18], two shots of $6.25 \mathrm{~kg}$ ogive-nosed steel projectiles were fired into a $2.0 \mathrm{~m}$ long and $1.6 \mathrm{~m}$ wide concrete cylinder cast in a steel culvert. The same striking velocity of $485 \mathrm{~m} / \mathrm{s}$ was achieved in the two shots. In the first shot, where a support was used at the rear face of the target, the depth of penetration was $655 \mathrm{~mm}$. The second shot, without support on the rear face, resulted in $660 \mathrm{~mm}$ penetration of the projectile. Hence, the support at the rear face of the target had a negligible effect on the depth of the penetration of the projectile. The diameter of the front-face crater was approximately $800 \mathrm{~mm}$ in both shots. The projectile had a length of $225 \mathrm{~mm}$, a diameter of $75 \mathrm{~mm}$, a density of $7830 \mathrm{~kg} / \mathrm{m}^{3}$, a bulk modulus of $159 \mathrm{GPa}$, a shear modulus of $81.8 \mathrm{GPa}$, and a yield stress of $792 \mathrm{MPa}$. The concrete cube strength was approximately $40 \mathrm{MPa}$ (tested on $150 \mathrm{~mm}$ cubes). 


\subsubsection{Studied bodies}

In order to study how the addition of steel fibres to the concrete affects the local damage (here measured as depth of penetration and crater sizes), numerical simulations of projectile impact on plain and steel-fibre reinforced concrete were conducted. Four different post-crack behaviours, representing one plain concrete (called NSC) and three different fibre-reinforced-concrete mixes (called FRC1, FRC2 and FRC3), were used in the simulations; further described in Section 3.2.2. The length, $L$, of the cylindrical target was varied, and two different striking velocities of the projectile, $v_{p r o j}$, were used in order to study the effect on the scabbing and perforation limit of the target. The simulations of plain concrete were also used to validate the numerical model by comparing the results to the findings from the benchmark experiment described in the previous section. Table 1 sums up the numerical simulations and shows the values of the parameters that vary in between them. The hydrocode AUTODYN-2D [19] was used for all simulations.

\subsubsection{Material models}

Since the primary effect of adding fibres to concrete is the improved post-cracking behaviour, and moderate volume fractions of steel fibres only result in minor effects on the ultimate tensile and compressive strengths, the only difference in the material models used for plain and steel-fibre-reinforced concretes is the failure description in tension, i.e. the post-crack behaviour. As discussed in Section 2.2 the addition of fibres may also somewhat affect the EOS, this effect is however not well known and since the generic behaviour of steel-fibre-reinforced concrete is reported to be the same as for plain concrete for moderate dosages of fibres, and that the effect of the somewhat increased density due to fibres is believed to be limited, this effect is not considered in the study.

In the simulations four different fracture energies were used, intended to correspond to the four different concretes; the plain concrete $\left(G_{F}=100 \mathrm{Nm} / \mathrm{m}^{2}\right)$ and three fibre-reinforced concretes $\left(G_{F}=2000,4000\right.$ and $\left.6000 \mathrm{Nm} / \mathrm{m}^{2}\right)$. The relation between the stress and crack opening in the postcrack regime was then simplified to a bi-linear relation according to Gylltoft [25] for plain concrete and according to Löfgren [33] for the steel-fibre-reinforced concretes; see Fig. 7. The empirical relations between the fracture energy and the parameters used to describe the bi-linear softening curve for a fibrereinforced concrete presented in Löfgren [33] (see section 2.2) is valid for concrete reinforced with the 
end-hooked steel fibre DRAMIX ${ }^{\mathrm{TM}}$ RC-65/35-BN. Therefore this type of fibre was assumed in this study.

In Table 2 the parameters for the bi-linear crack-softening relation and approximate values of corresponding steel-fibre volume fractions calculated according to [33] for the fibre-reinforced concretes are shown together with the values used for simulations of plain concrete targets.

The RHT material model, developed by Riedel, Hiermayer and Thoma [35], was used for modelling of both the plain and fibre-reinforced concretes. It consists of three different pressure dependant surfaces which are different limit states for the yield surface; the elastic limit, the failure, and the residual strength. Beside the pressure dependency of the yield surface, which takes into account the material strength increase with an increasing hydrostatic pressure, the model also includes the effects of strain and strainrate hardening, and the loading path. The strain-rate dependence is taken into account by expanding the failure surface in the stress space where the degree of expansion depends on the hydrostatic stresses, i.e. the dynamic increase effect is larger for tensile than compressive states of stress. The effect of the loading path on the yield surface is taken into account by a dependence of the third invariant.

However, it is not possible to describe different post-crack behaviours in the standard RHT material model, which uses a hydrodynamic-tensile-failure model where tensile failure is assumed to occur if the value of the hydrodynamic pressure in a cell falls below a specified limit. A modified crack-softening behaviour could only be used in combination with the principal-stress-failure model. When using a modified crack-softening law, the strain-rate dependence of the tensile strength, used in the standard RHT strength model, is cut off. This means that the tensile strength will be unaffected by the strain rate. In an attempt to reintroduce strain-rate dependence in tension, by use of a subroutine, it was found that this could not be done without getting unwanted effects on the crack-softening behaviour, such as serious underestimations of the fracture energy. This problem arises from the requirement, built into the program, that the user-defined tensile stress is used only if it falls inside the RHT failure surface. The parameter $\delta$, used to describe the strain-rate dependence in tension in the RHT model, was set to zero in simulations where the modified RHT material model was used. This means that no strain-rate dependence for the ultimate tensile strength is taken into account in these simulations.

In AUTODYN [19] a linear crack-softening law is used to describe the post-crack behaviour in tension. However, the bi-linear crack-softening law described above is more convenient to use for concrete, since it is a very brittle material and the strength decreases rapidly after the failure initiation. 
Hence, a modification of the model, allowing for a multi-linear crack-softening relation, has been developed and used in the simulations. In order to determine the relation between stress and strain for the crack softening, necessary for calculations in programs following a smeared crack approach, e.g.

AUTODYN, a relation between the crack opening, $w$, and the strain, $\varepsilon$, must be assumed. The crack width is smeared out over a length $l_{e l}$, which is related to the size of the local element. In AUTODYN the length $l_{e l}$ is calculated as the diameter of a sphere whose volume equals the volume of the local element [19].

The steel (i.e. the projectile and confining steel around the concrete) is modelled with the von Mises material model without any strain hardening and with a linear EOS. Material parameters for the concrete used in the numerical simulations are shown in Appendix A.

\subsubsection{Mesh}

It is well known that the size of the elements used in a numerical mesh affects the results, and that a refined mesh extends the computational time. In the simulations, made in $2 \mathrm{D}$ with axial symmetry, quadratic Lagrangian elements with length $5 \mathrm{~mm}$ were used for the concrete target. Based on experience, this element size was found to give reasonable results and a finer mesh was believed not to give an increased accuracy worth the increased computational time. The projectile was modelled with 4 elements across the radius and totally 8 and 4 elements along the length for the ogive-nosed and flat-nosed projectiles, respectively. For the $2 \mathrm{~m}$ long concrete target, the steel culvert also covers the rear face of the target, while it does not in the simulations with the shorter cylinders (i.e. 1.0, 1.1 and 1.3 m long targets). Full interaction between the steel culvert and the concrete is assumed in all cases. The numerical mesh for simulations NSCs001 and NSCs003 is shown in Fig. 8.

\section{Results}

The results, i.e. the depth of penetration and crater size on front and rear face of the concrete target, from simulations described in section 3.2 are shown in Table 3.

It is to be observed that the size of the crater diameter is ambiguous and depends on the way chosen to analyse the results. In Fig. 9 magnifications of the front-face crater and different ways to measure its size are shown for case NSCs001. In this study an unsmooth-damage plot is used to measure the crater size as shown in Fig. 9a. The crater size is estimated as the distance from the central axis to the outermost continuous crack, i.e. continuous line of fully damaged (red) elements, which reaches the front face of the 
cylinder. Fig. 9b shows a similar way to estimate the crater size, but here a smoothed-damage plot is used instead of an unsmoothed-damage plot. However, the unsmoothed-damage plot is believed to give a more fair representation of the crater size since it shows the level of damage in each element as it is calculated in the simulation and not when the damage in an element is smoothed out over a greater area. In the method shown in Fig. 9c node-velocity vectors are used to estimate the crater size. In this case the crater is assumed to reach the place where the nodes are not moving out of the concrete body. This method does require that the simulations are long enough to make sure that this point does not move. It is believed that the method used in this study (shown in Fig. 9a) is the most appropriate way to measure the size of the crater after penetration of the projectile.

\subsection{Validation of the numerical model}

The standard RHT material model gives a close approximation of the depth of penetration and crater size on the front face of the concrete target, which can be seen when comparing the results from simulation NSC001 to the results from the experiment described in section 3.1; see Fig. 10a. However, the cavitated region in the results from this simulation should have been narrower in order to agree with the experimental results. Since no data of the cavitated region in the experiments are presented in [18] this is not shown in Fig. 10a.

As described in Section 3.2.2 the change from the standard RHT material model to the modified RHT material model used in the comparative study included:

- Turning off the strain-rate dependence for the ultimate tensile strength.

- Using a principal-stress tensile-failure model instead of the hydrodynamic tensile-failure model.

- Using a bi-linear crack-softening relation instead of a linear one.

The results of the simulations where these changes are made one by one (simulations NSC002, NSC003 and NSCs001, respectively) are shown in Fig. $10 \mathrm{~b}$ to d.

When using a strain-rate independence for the tensile strength ( $\delta=0$ in the RHT material model) the depth of penetration increases by $25 \%$ compared to the case where the dynamic effect of the tensile strength is taken into account, as seen in Fig. 10b. Changing from a hydrodynamic-tensile-failure model to a principal-tensile-stress-failure model gives a further increase of the depth of penetration with approximately 20\%; see Fig. 10c. Using a bi-linear crack-softening law for the simulations with plain 
concrete results in a small decrease of the depth of penetration but a rather large increase of the front-face crater size compared to the simulation with principal-stress tensile-failure model and a linear cracksoftening law; see Fig. 10d.

It can be concluded that the use of the modified RHT material model instead of the standard version lead to results where the depth of penetration and the size of the front face crater exceed the experimental measurements by 28 and $45 \%$, respectively. Hence, it must be pointed out that the simulation results of projectile impact in fibre-reinforced concrete presented in this study are not showing the real behaviour and cannot be used to draw quantified conclusions, but are showing the relative influence of different parameters and can therefore be used in a qualitative manner.

\subsection{Effect of fibres in concrete}

The relative effect on the local damage of adding fibres to plain concrete can be seen by comparing the results of the numerical simulations starting with NSCs, FRC1, FRC2 and FRC3 in Table 3.

\section{2 metre long cylinder (simulations NSCS001, FRC1001, FRC2001 and FRC3001)}

In Fig. 11 the results for two of the fibre-reinforced concretes are shown in the case of a 2.0 metre long cylinder, namely FRC1001 and FRC3001. When comparing these results with the case of plain concrete (in Fig. 10d) it can be seen that the addition of fibres has a minor influence on the depth of penetration, but also that the influence on the front-face crater size is considerable. The addition of fibres also gives reduced crack propagation beyond the crater region, so that damage becomes confined to a more localised volume. In Fig. 11 it can also be seen that an increased volume fraction of fibres only has a small influence on the front-face crater size, while the crack propagation beyond the crater region is still reduced. A possible explanation to this difference is that the crack propagation beyond the crater region is due to tensile failure in the concrete, while the front-face crater is also due to crushing. This means that the reduction of the front-face crater size is limited by the limited change in crushing properties of the concrete when fibres are added or the volume fraction of fibres is increased.

\section{3 metre long cylinder (simulations NSCs004, FRC1004, FRC2004 and FRC3004)}

Decreasing the length of the cylinders from 2.0 to 1.3 metres only leads to minor effects on the depth of penetration and the diameter of the front-face crater, and even tough almost $75 \%$ of the cylinders are 
penetrated scabbing does not occur. The findings about the effects of fibres for the 2.0 metre long cylinder also hold for this case.

\section{1 metre long cylinder (simulations NSCs002, FRC1002, FRC2002 and FRC3002)}

Further shortening of the concrete cylinder to 1.1 metre results in the formation of a scabbing crater on the rear face of the cylinder for plain as well as fibre-reinforced concrete. However, the scabbing could not be differentiated from perforation for the ogive-nosed projectile due to the formation of a punchingshear plug. The size of the scabbing crater is highly influenced by the addition of fibres and, contrary to the size of the front-face crater, also to an increased amount of fibres.

1.0 metre long cylinder, flat-nosed projectile (simulations NSCs003, FRC1003, FRC2003 and FRC3003)

In order to study the effect of fibres for scabbing caused only by the reflected stress wave and not in combination with plugging effects from the projectile, the simulations of a 1.0 metre long concrete cylinder, and a flat-nosed projectile with striking velocity of $650 \mathrm{~m} / \mathrm{s}$, were conducted. The results of these simulations are shown in Fig. 12, where it can be seen that scabbing occurs in the case of plain concrete, but is prevented when fibres are added to the concrete. Even though crack initiation takes place also for the fibre-reinforced concretes the fibres prevent the initiated crack from developing into a continuous crack.

\section{Discussion}

Experimental studies performed around the world [3-11] have shown that the addition of fibres to concrete affects the damage caused by impact, but the structural behaviours of targets subjected to highvelocity impact are complicated. In order to further study how the addition of various volume fractions of fibres to concrete affect the projectile resistance, numerical simulations were conducted in the programme AUTODYN.

Due to limitations in the numerical-simulation tool, the strain-rate dependence in tension for concrete used in the RHT material model, often used for modelling concrete subjected to projectile or fragment impact, could not be used in combination with a modified crack-softening curve. 
When using the standard RHT material model in the numerical simulations the depth of penetration and crater diameter on the front face of the $2.0 \mathrm{~m}$ long concrete target agree well with the experimental results. However, the size of the cavitated region is overestimated in the numerical simulation, which, according to [19], may be explained by the simplicity of the hydrodynamic tensile failure. In [19] it is also pointed out that users of the model should avoid drawing conclusions from details within the spalled or cavitated regions. Since the standard RHT material model cannot be used with a modified cracksoftening law, necessary to capture the effect of the added fibres in the concrete, the principal-tensilestress-failure model was used instead of the hydrodynamic-tensile-failure model in the simulations, which also means that the strain-rate dependence of the tensile strength is turned off. These changes led to an increased depth of penetration. The increment caused by the strain-rate independence of the tensile strength was expected since the depth of penetration depends on the tensile strength, but the increased penetration depth due to the change of tensile failure model probably derives from the different ways of taking the third invariant and its dependence on the hydrostatic pressure into account.

Since the fibre-reinforced concrete is not modelled as discrete fibres within a concrete matrix, but the fibres and concrete are instead modelled as one material with an improved post-cracking behaviour compared to plain concrete, the results must be used with care. There are effects of the fibres that get lost due to this simplification. Furthermore, since the effect of the fibres is not notable until after tensilefailure initiation in the concrete (i.e. crack initiation), the results are highly dependent on the crack distribution within the concrete target. The possibility to predict the real crack distributions within a concrete target by means of numerical-simulation tools is strictly limited, and it should therefore be pointed out that the results presented in this paper should be used in a comparative way and the reader should treat the results with care and avoid drawing conclusions from details in the results.

The relative effect of fibres added to the concrete mix was found by comparing results from simulations of projectile impact on plain concrete, modelled with bi-linear crack-softening in tension, to projectile impact on fibre-reinforced concrete also modelled with bi-linear crack softening, but with larger fracture energies than in plain concrete. In agreement with the literature [9] it was found that the addition of fibres has a negligible effect on the depth of penetration, while it decreases the crater size on both the front and rear face of the target. The influence on the scabbing crater is found to be larger than on the spalling crater, which can be explained by the fact that a considerable part of the damage in the front-face 
crater is caused by crushing of the material while the scabbing crater is mainly caused by tensile failure, for which the effect of the fibres is larger. For the same reason the effect of increasing the number of fibres is more visible on the rear-face crater than on the front-face crater. As mentioned in Section 4.2 this argument also holds for the crack propagation beyond the crater region which is reduced as the volume fraction of fibres is increased.

\section{Conclusions}

The comparative numerical study of the resistance of fibre-reinforced concrete and plain concrete to projectile impact showed that the addition of moderate dosage $(<1 \%)$ of fibres to concrete gives:

- A negligible decrease of projectile-penetration depth compared to plain concrete.

- A decrease of crater diameter on both front and rear faces of the concrete target, but where the effect on the rear face is larger than on the front face.

○ Reduced crack propagation beyond the crater region, so that damage is confined to a more localized volume.

An increasing amount of fibres in the concrete results in a:

- Relatively small change of the front-face crater size.

- Decreasing diameter of the rear-face crater in cases where scabbing occurs.

○ Reduced crack propagation beyond the crater region.

It can also be concluded that scabbing in concrete structures caused by projectile impact may be prevented by use of fibre-reinforced concrete if scabbing is due to the reflected stress wave caused by the impact alone, and not in combination with the shear-plugging effects from the projectile.

\section{Acknowledgement}

The research presented in this paper is done within the research project "Concrete structures subjected to blast and fragment impacts: dynamic behaviour of reinforced concrete", financially supported by the Swedish Rescue Services Agency. The authors would like to thank the members of the reference group for the research project: Björn Ekengren, M.Sc., at the Swedish Rescue Services Agency, Morgan Johansson, Ph.D., at Reinertsen AB, and Joosef Leppänen, Ph.D., at FB Engineering AB. 
Appendix A Model input data

Input data for concrete and steel-fibre reinforced concrete: RHT model.

\begin{tabular}{|c|c|c|}
\hline Parameter & Value & Comments \\
\hline Shear Modulus [kPa] & $1.433 \cdot 10^{7}$ & $\mathrm{a}$ \\
\hline Compressive Strength $f_{c}[\mathrm{kPa}]$ & $3.38 \cdot 10^{4}$ & $\mathrm{a}$ \\
\hline Tensile Strength $f_{t} / f_{c}$ & 0.078 & $\mathrm{a}$ \\
\hline Shear Strength $f_{s} / f_{c}$ & 0.18 & $\mathrm{~b}$ \\
\hline Intact Failure Surface Constant $A$ & 2 & \\
\hline Intact Failure Surface Exponent $N$ & 0.7 & $\mathrm{c}$ \\
\hline Tens./Compr. Meridian Ratio & 0.6805 & $\mathrm{~b}$ \\
\hline Brittle to Ductile Transition & 0.0105 & $\mathrm{~b}$ \\
\hline $\mathrm{G}$ (elastic)/G(elastic-plastic) & 2 & $\mathrm{~b}$ \\
\hline Elastic Strength $/ f_{t}$ & 0.7 & $\mathrm{~b}$ \\
\hline Elastic Strength $/ f_{c}$ & 0.53 & $\mathrm{~b}$ \\
\hline Fractured Strength Constant $B$ & 1.5 & $\mathrm{c}$ \\
\hline Fractured Strength Exponent $M$ & 0.7 & $\mathrm{c}$ \\
\hline Compressive Strain Rate Exponent $\alpha$ & 0.032 & $\mathrm{~b}$ \\
\hline Tensile Strain Rate Exponent $\delta$ & $0,0.025$ & $\mathrm{~d}$ \\
\hline Maximum Fracture Strength Ratio & $1 \cdot 10^{20}$ & $\mathrm{~b}$ \\
\hline Use CAP on Elastic Surfac & Yes & $\mathrm{b}$ \\
\hline Damage Constant $D 1$ & 0.04 & $\mathrm{~b}$ \\
\hline Damage Constant $D 2$ & 1 & $\mathrm{~b}$ \\
\hline Minimum Strain to Failure & 0.01 & $\mathrm{~b}$ \\
\hline Residual Shear Modulus Fraction & 0.13 & $\mathrm{~b}$ \\
\hline Tensile Failure & Hydro, Principal Stress & $\mathrm{e}$ \\
\hline Principal Tensile Failure Stress [kPa] & $2.6364 \cdot 10^{3}$ & \\
\hline Maximum Principal Stress Difference/2 & $1.01 \cdot 10^{20}$ & $\mathrm{~b}$ \\
\hline Crack softening & Yes & \\
\hline Fracture energy $\left[\mathrm{Nm} / \mathrm{m}^{2}\right]$ & $100,2000,4000,6000$ & $\mathrm{f}$ \\
\hline
\end{tabular}


Flow Rule

Stochastic Failure

Erosion Strain/Instantaneous Geometric Strain
No-bulking

No

1.5 b

$\mathrm{b}$

g

a. Calculated according to CEB-FIB Model Code 1990 [24].

b. Default value in AUTODYN material library for concrete with compressive strength of $35 \mathrm{MPa}$.

c. Determined by Leppänen [21], based on model proposed by Attard and Setunge [37].

d. No strain-rate dependence of tensile strength used in combination with modified RHT material model: for standard RHT model the $\delta$ parameter is set to 0.025 .

e. Principal-stress-failure model is used in modified RHT material model, and hydrodynamic-tensilefailure model for standard RHT material model.

f. $G_{F}=100 \mathrm{Nm} / \mathrm{m}^{2}$ for plain concrete and $G_{F}=2000,4000$ and $6000 \mathrm{Nm} / \mathrm{m}^{2}$ for the steel-fibre reinforced concrete.

g. Calibrated by parameter studies; see Nyström [23]. 
Input data for concrete: equation of state (EOS).

\begin{tabular}{ll}
\hline Parameter & Value \\
\hline Reference Density $\left[\mathrm{g} / \mathrm{cm}^{3}\right]$ & 2.75 \\
Porous Density $\left[\mathrm{g} / \mathrm{cm}^{3}\right]$ & 2.4 \\
Porous Sound Speed $[\mathrm{m} / \mathrm{s}]$ & 2920 \\
Initial Compaction Pressure $[\mathrm{kPa}]$ & $2.33 \cdot 10^{4}$ \\
Solid Compaction Pressure $[\mathrm{kPa}]$ & $6 \cdot 10^{6}$ \\
Compaction Exponent & 3 \\
Solid EOS & Polynomial \\
Bulk Modulus A1 $[\mathrm{kPa}]$ & $3.527 \cdot 10^{7}$ \\
A2 $[\mathrm{kPa}]$ & $3.958 \cdot 10^{7}$ \\
A3 $[\mathrm{kPa}]$ & $9.04 \cdot 10^{6}$ \\
$B 0$ & 1.22 \\
B1 & 1.22 \\
$T 1$ & $3.527 \cdot 10^{7}$ \\
T2 & 0 \\
Reference Temperature $[\mathrm{K}]$ & 300 \\
Specific Heat $[\mathrm{J} / \mathrm{kgK}]$ & 654 \\
Thermal Conductivity $[\mathrm{J} / \mathrm{mKs}]$ & 0 \\
\hline & Standard \\
\hline
\end{tabular}




\section{References}

[1] Kennedy RP. A review of procedures for the analysis and design of concrete structures to resist missile impacts. Nucl Eng Des 1976;37:183-203.

[2] Vossoughi F, Ostertag CP, Monteiro PJM, Johnson GC. Resistance of concrete protected by fabric to projectile impact. Cem Concr Res 2007;37:96-106.

[3] Zhanga MH, Shimb VPW, Lua G, Chewa CW. Resistance of high-strength concrete to projectile impact. Int J Impact Engng 2005;31:825-841.

[4] Maalej M, Quek SR, Zhang J. Behavior of hybrid-fiber engineered cementitious composites subjected to dynamic tensile loading and projectile impact. J Mater Civil Eng 2005;17(2):143-152.

[5] Nataraja MC, Nagaraj TS, Basavaraja SB. Reproportioning of steel fibre reinforced concrete mixes and their impact resistance. Cem Concr Res 2005;35:2350-2359.

[6] Luo X, Sun W, Chan SYN. Characteristics of high-performance steel fiber-reinforced concrete subject to high velocity impact. Cem Concr Res 2000;30:907-914.

[7] Ong KCG, Basheerkhan M, Paramasivam P. Resistance of fibre concrete slabs to low velocity projectile impact. Cem Concr Res 1999;21:391-401.

[8] Cánovas MF, Pamies RG, Simón del Potro JR, Almansa EM. Impact effects on the primary fragmentation generated by the HE81 mortar grenade on conventional concrete and steel fibers reinforced concrete. In: Bulson PS (ed.). Proceedings of the Third International Conference on Structures Under Shock and Impact, Madrid (Spain): Computational Mechanics Publications, 1994, pp. 37-44.

[9] Almansa, EM, Cánovas MF. Behaviour of normal and steel fiber-reinforced concrete under impact of small projectiles. Cem Concr Res 1999;29:1807-1814.

[10] Dancygier, AN, Yankelevsky, DZ, Jaegermann, CH. Response of high performance concrete plates to impact of non deforming projectiles. Int J Impact Engng 2007;34(11):1768-1779.

[11] Dancygier, AN, Yankelevsky, DZ. High-strength concrete response to hard projectile impact. Int J Impact Engng 1996;18(6):583-599.

[12] Corbett GG, Reid SR, Johnson W. Impact loading of plates and shells by free-flying projectiles: A review. Int J Impact Engng 1996;18(2):141-230. 
[13] Chen XW, Li QM. Deep penetration of a non-deformable projectile with different geometrical characteristics. Int J Impact Engng 2002;27:619-637.

[14] Chen XW, Li QM. Oblique and normal perforation of concrete targets by a rigid projectile. Int J Impact Engng 2004;30:617-637.

[15] Tham CY. Numerical and empirical approach in predicting the penetration of a concrete target by an ogive-nosed projectile. Finite Elem Anal Des 2006;42:1258-1268.

[16] Chen XW, Li QM. Dimensionless formulae for penetration depth of concrete target impacted by a non-deformable projectile. Int J Impact Engng 2003;28:93-116.

[17] Forrestal MJ, Frew DJ, Hanchak SJ, Brar NS. Penetration of grout and concrete targets with ogivenose steel projectiles. Int J Impact Engng 1996;18(5):465-476.

[18] Hansson H. Numerical simulation of concrete penetration. FOA report 98-00816--311--SE, Defence research establishment, Tumba (Sweden), 1998, 17 pp.

[19] ANSYS AUTODYN User Manual, Version 11.0. Concord (CA, USA): Century Dynamics Inc., 2007. 528 pp.

[20] Johansson M. Structural Behaviour in Concrete Frame Corners of civil Defence Shelters, Non-linear Finite Element Analyses and Experiments. Doctoral Thesis, Department of Structural Engineering, Concrete Structures, Göteborg (Sweden): Chalmers University of Technology, 2000. 220 pp.

[21] Leppänen J. Concrete Structures Subjected to Fragment Impacts, Dynamic Behaviour and Material Modelling. Doctoral Thesis, Department of Structural Engineering and Mechanics, Concrete Structures, Göteborg (Sweden): Chalmers University of Technology, 2004. 127 pp.

[22] Nyström U. Design with regard to explosions. Master's Thesis, Department of Civil and Environmental Engineering, Structural Engineering, Concrete Structures, Göteborg (Sweden): Chalmers University of Technology, 2006. 205 pp.

[23] Nyström U, Leppänen J. Numerical Studies of Projectile Impacts on Reinforced Concrete. In: Fan SC, Chua HK (eds.). Proceedings of the Second International Conference on Design and Analysis of Protective Structures, Singapore (Singapore): Nanyang Technical University, 2006. p. 310-319.

[24] CEB-FIP Model Code 1990. Design Code, Lausanne, Switzerland: Thomas Telford. 1993. 437pp.

[25] Gylltoft K. Fracture mechanics models for fatigue in concrete structures. Doctoral Thesis, Division of Structural Engineering, Luleå (Sweden): Luleå University of Technology, 1983. 210 pp. 
[26] van Mier JGM. Strain-softening of concrete under multiaxial loading conditions. Doctoral Thesis, Eindhoven (The Netherlands): Eindhoven University of Technology, 1984. 349 pp.

[27] Bischoff PH, Perry SH. Compressive behaviour of concrete at high strain rates. Mater Struct 1991;24:425-450.

[28] Ross CA, Jerome DM, Tedesco JW, Hughes ML. Moisture and strain rate effects on concrete strength. ACI Mater J 1996;93(3):293-300.

[29] Weerheijm J. Concrete under Impact Tensile Loading and Lateral Compression. Doctoral Thesis, Delft University of Technology, Delft (The Netherlands), 1992.

[30] Schuler H. Experimentelle und numerische Untersuchungen zur Schädigung von stoßbeanspruchtem Beton (in German). Doctoral Thesis, Universität der Bundeswehr München, Freiburg (Germany): Intitut Kurzzeitdynamik, Ernst-Mach-Institut, 2004. 184 pp.

[31] Brara A, Klepaczko JR. Fracture energy of concrete at high loading rates in tension. Int J Impact Engng 2007;34(3):424-435.

[32] Weerheijm J, van Doormaal JCAM. Tensile failure of concrete at high loading rates: New test data on strength and fracture energy from instrumented spalling tests. Int J Impact Engng 2007;34(3):609-626.

[33] Löfgren I. Fibre-reinforced concrete for industrial construction: a fracture mechanics approach to material testing and structural analysis. Doctoral Thesis, Department of Civil and Environmental Engineering, Structural Engineering, Göteborg (Sweden): Chalmers University of Technology, 2005. 243 pp.

[34] Greulich S. Zur numerischen Simulation von Stahlbeton- und Faserbetonstrukturen unter Detonationsbeanspruchung (in German). Doctoral Thesis, Universität der Bundeswehr München (Germany). 2004. 255 pp.

[35] Riedel W. Beton unter dynamischen lasten, meso. und makromechanische modelle und ihre parameter (in German). Doctoral Thesis, Universität der Bundeswehr München, Freiburg (Germany): Institut Kurzzeitdynamik, Ernst-Mach-Institut, 2000. 210 pp.

[36] Landmann F. dokumentation der Parameteruntersuchungen des Schädigungverhaltens von Stahlbetonplatten unter Kontaktdetonation (in German). Zwischenbericht der Wehrtechnischen Dienststelle für Schutz- und Sondertechnik (WTD52), Oberjettenberg (Germany), 2001. 
[37] Attard MM, Setung S. Stress-strain relationship of confined and unconfined concrete. ACI Mater J 1996;93(5):432-442. 
Fig. 1. (a) Schematic view of the stress-strain relationship for concrete and (b) the relation between tensile and compressive strengths (uni-axial loading) according to CEB FIP Model Code 1990 [24].

Fig. 2. Bi-linear and power function, respectively, describing the softening after failure initiation in concrete under uni-axial tension.

Fig. 3. Equation of state for concrete; from Leppänen [21].

Fig. 4. Relation between dynamic increase factor for fracture energy and crack-opening velocity for concrete, according to Schuler [30].

Fig. 5. Bi-linear stress-crack opening relation for steel-fibre reinforced concrete.

Fig. 6. Schematic illustration of study procedure, where NSC is Normal-Strength Concrete and FRC is Fibre-Reinforced Concrete.

Fig. 7. Crack softening for concrete NSC, FRC1, FRC2 and FRC3.

Fig. 8. Numerical mesh for simulation NSCs001 and NSCs003.

Fig. 9. Magnifications of the front-face crater for case NSCs001 with estimations of its size by use of plots with (a) unsmoothed damage (which is the method used in the presented study), (b) smoothed damage and (c) node-velocity vectors.

Fig. 10. Simulation results for plain concrete, case (a) NSC001 with standard RHT material model, (b) NSC002 where no strain-rate dependence for tensile strength is used, (c) NSC003 with principaltensile stress failure, and (d) NSCs001 with a bi-linear crack-softening law. The arrows in (a) indicate the crater diameter and penetration depth reported by Hansson [18]. A damage bar is also shown in the figure. 
Fig. 11. Simulation results for fibre-reinforced concrete, cases FRC1001 and FRC3001.

Fig. 12. Simulation results for plain (NSCs003) and fibre-reinforced concrete (FRC1003 and FRC3003). 


\section{Table 1}

Numerical simulations.

Table 2

Bi-linear crack-softening-relation parameters for steel-fibre reinforced concrete.

Table 3

Simulation results 


\begin{tabular}{|c|c|c|c|c|c|c|}
\hline Ident & Concrete & $\begin{array}{c}\text { Tensile failure } \\
\text { model }^{\text {a }}\end{array}$ & $\sigma$-w curve & $\delta[-]^{\mathrm{a}}$ & $L[\mathrm{~mm}]$ & $v_{p r o j}[\mathrm{~m} / \mathrm{s}]$ \\
\hline NSC001 & NSC & Hydro & - & 0.025 & 2000 & 485 \\
\hline NSC002 & NSC & Hydro & - & 0 & 2000 & 485 \\
\hline NSC003 & NSC & Principal Stress & Linear & 0 & 2000 & 485 \\
\hline NSCs001 & NSC & Principal Stress & Bi-linear & 0 & 2000 & 485 \\
\hline NSCs002 & NSC & Principal Stress & Bi-linear & 0 & 1100 & 485 \\
\hline NSCs003 & NSC & Principal Stress & Bi-linear & 0 & 1000 & $650^{\mathrm{b}}$ \\
\hline NSCs004 & NSC & Principal Stress & Bi-linear & 0 & 1300 & 485 \\
\hline FRC1001 & FRC1 & Principal Stress & Bi-linear & 0 & 2000 & 485 \\
\hline FRC1002 & FRC1 & Principal Stress & Bi-linear & 0 & 1100 & 485 \\
\hline FRC1003 & FRC1 & Principal Stress & Bi-linear & 0 & 1000 & $650^{\mathrm{b}}$ \\
\hline FRC1004 & FRC1 & Principal Stress & Bi-linear & 0 & 1300 & 485 \\
\hline FRC2001 & FRC2 & Principal Stress & Bi-linear & 0 & 2000 & 485 \\
\hline FRC2002 & FRC2 & Principal Stress & Bi-linear & 0 & 1100 & 485 \\
\hline FRC2003 & FRC2 & Principal Stress & Bi-linear & 0 & 1000 & $650^{\mathrm{b}}$ \\
\hline FRC2004 & FRC2 & Principal Stress & Bi-linear & 0 & 1300 & 485 \\
\hline FRC3001 & FRC3 & Principal Stress & Bi-linear & 0 & 2000 & 485 \\
\hline FRC3002 & FRC3 & Principal Stress & Bi-linear & 0 & 1100 & 485 \\
\hline FRC3003 & FRC3 & Principal Stress & Bi-linear & 0 & 1000 & $650^{\mathrm{b}}$ \\
\hline FRC3004 & FRC3 & Principal Stress & Bi-linear & 0 & 1300 & 485 \\
\hline
\end{tabular}

${ }^{a}$ Brief descriptions of tensile-failure models and the parameter $\delta$ are found in section 3.2.2; for further documentation see [19]. If $\delta \neq 0$, strain-rate effects on ultimate tensile strength are taken into account.

b A $4.5 \mathrm{~kg}$, flat-nosed, steel projectile was used in these simulations. 


\begin{tabular}{lrrrrrrrr}
\hline \multicolumn{1}{c}{ Concrete } & \multicolumn{1}{c}{$\begin{array}{c}G_{F} \\
{\left[\mathrm{Nm} / \mathrm{m}^{2}\right]}\end{array}$} & $\begin{array}{c}a_{1} \\
{\left[\mathrm{~mm}^{-1}\right]}\end{array}$ & $\begin{array}{c}a_{2} \\
{\left[\mathrm{~mm}^{-1}\right]}\end{array}$ & $\begin{array}{c}b_{2} \\
{\left[\mathrm{~mm}^{-1}\right]}\end{array}$ & $\begin{array}{c}w_{l} \\
{[\mathrm{~mm}]}\end{array}$ & $\begin{array}{c}w_{c} \\
{[\mathrm{~mm}]}\end{array}$ & $\begin{array}{c}\text { No offibres } \\
{\left[\# / \mathrm{cm}^{2}\right]}\end{array}$ & $\begin{array}{c}V_{f} \\
{[\%]}\end{array}$ \\
\hline NSC & 100 & 26.4 & 2.64 & 0.4 & 0.025 & 0.152 & 0 & 0 \\
FRC1 & 2000 & 26.4 & 1.32 & 0.445 & 0.021 & 3.379 & 0.403 & 0.20 \\
FRC2 & 4000 & 26.4 & 1.32 & 0.632 & 0.014 & 4.794 & 1.074 & 0.50 \\
FRC3 & 6000 & 26.4 & 1.32 & 0.774 & 0.0086 & 5.875 & 1.587 & 0.75 \\
\hline
\end{tabular}




\begin{tabular}{|c|c|c|c|}
\hline Ident & $\begin{array}{c}\text { Depth of penetration } \\
{[\mathrm{mm}]}\end{array}$ & $\begin{array}{l}\text { Crater diameter on } \\
\text { front face }[\mathrm{mm}]\end{array}$ & $\begin{array}{l}\text { Crater diameter on } \\
\text { rear face }[\mathrm{mm}]\end{array}$ \\
\hline NSC001 & 660 & 800 & 0 \\
\hline NSC002 & 825 & 740 & 0 \\
\hline NSC003 & 1000 & 700 & 0 \\
\hline NSCs001 & 960 & 1020 & 0 \\
\hline NSCs002 & perforation & 860 & 890 \\
\hline NSCs003 & 480 & 840 & 980 \\
\hline NSCs004 & 960 & 920 & 0 \\
\hline FRC1001 & 880 & 560 & 0 \\
\hline FRC1002 & perforation & 640 & \\
\hline FRC1003 & 430 & 660 & 0 \\
\hline FRC1004 & 950 & 700 & 0 \\
\hline FRC2001 & 900 & 520 & 0 \\
\hline FRC2002 & perforation & 540 & 530 \\
\hline FRC2003 & 425 & 660 & 0 \\
\hline FRC2004 & 890 & 560 & 0 \\
\hline FRC3001 & 890 & 550 & 0 \\
\hline FRC3002 & perforation & 550 & 460 \\
\hline FRC 3003 & 400 & 660 & 0 \\
\hline FRC3004 & 915 & 570 & 0 \\
\hline
\end{tabular}




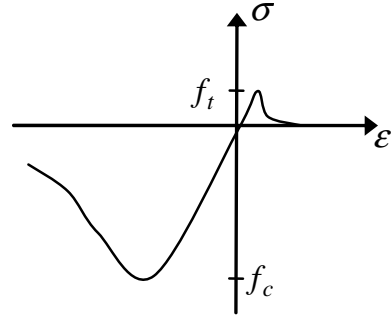

a)

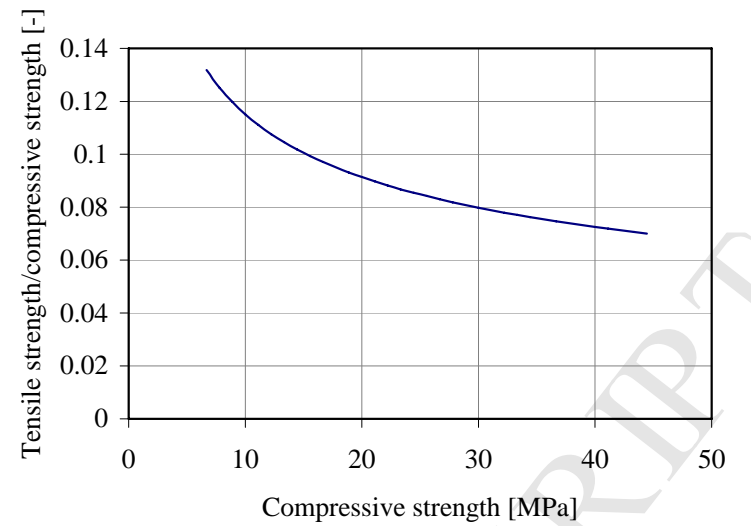

b) 


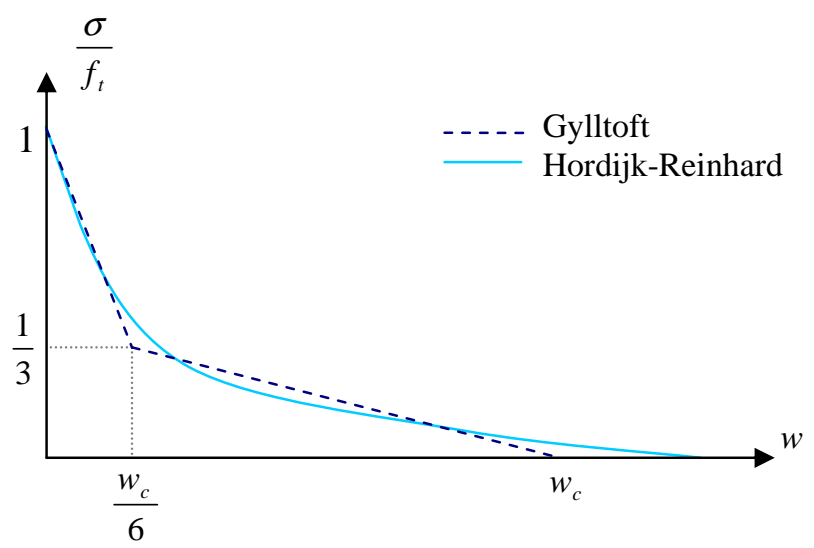




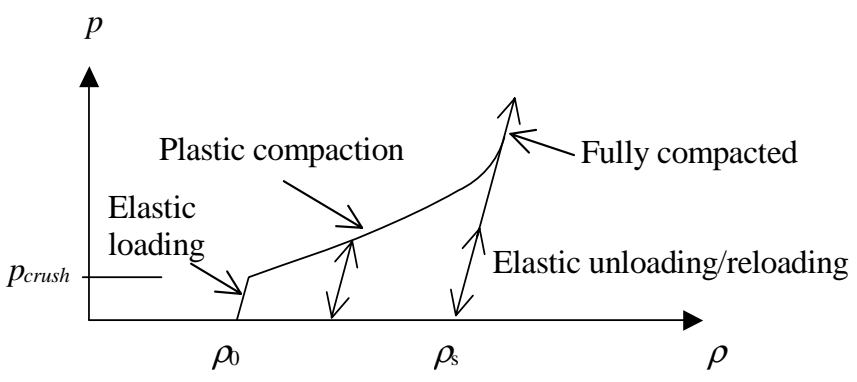




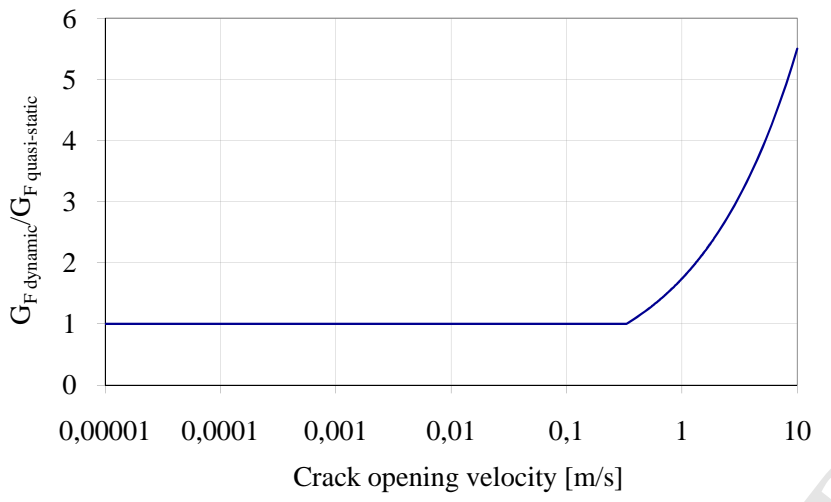




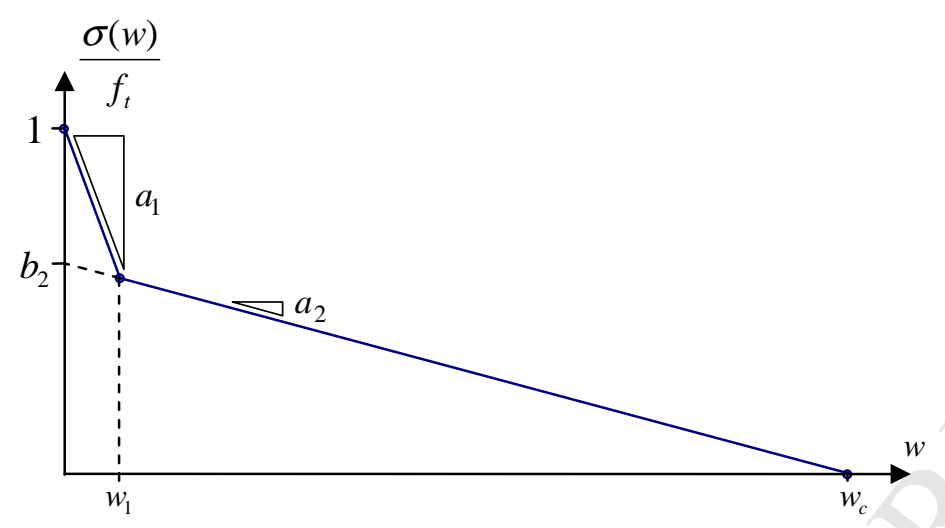




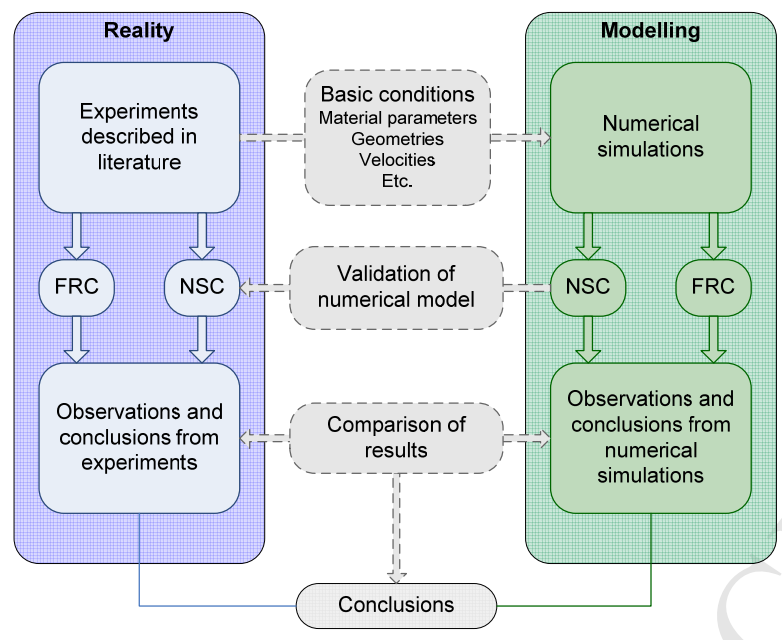




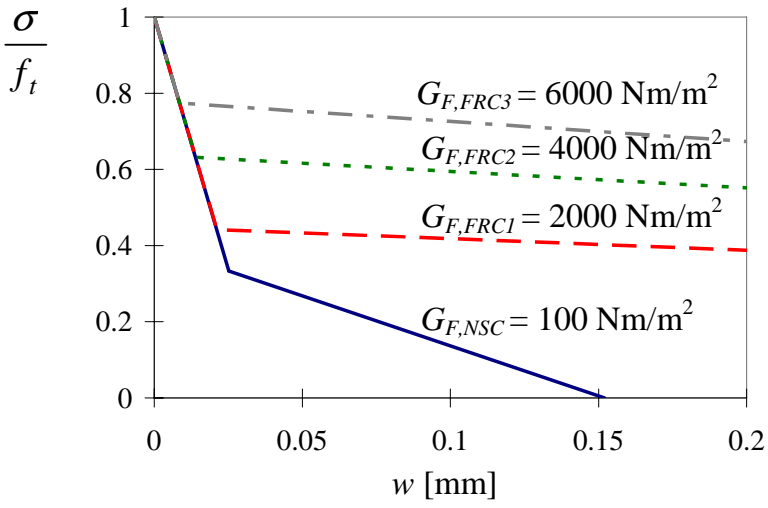




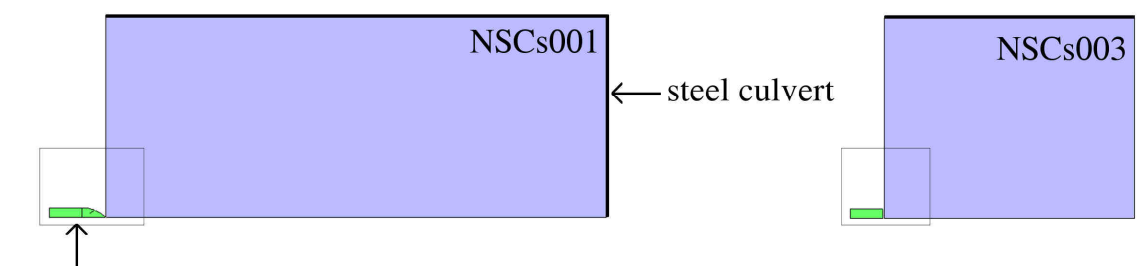

projectile
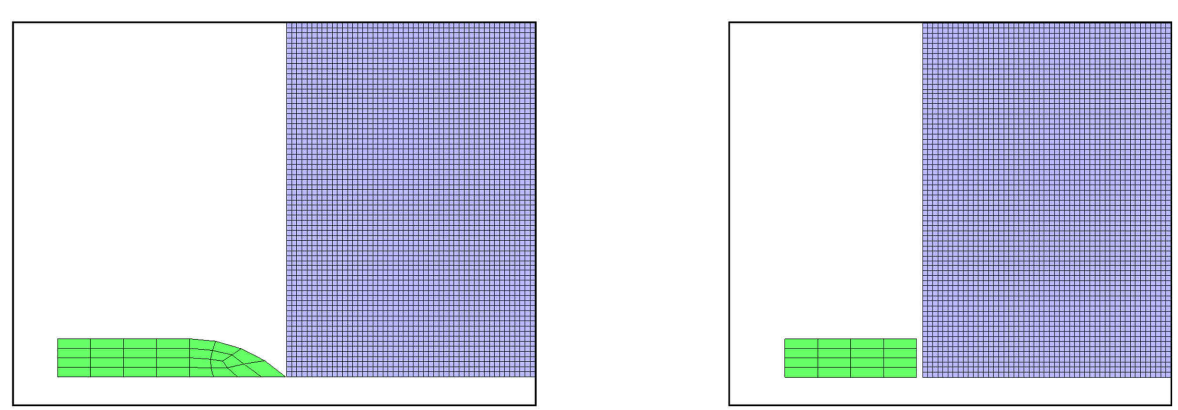

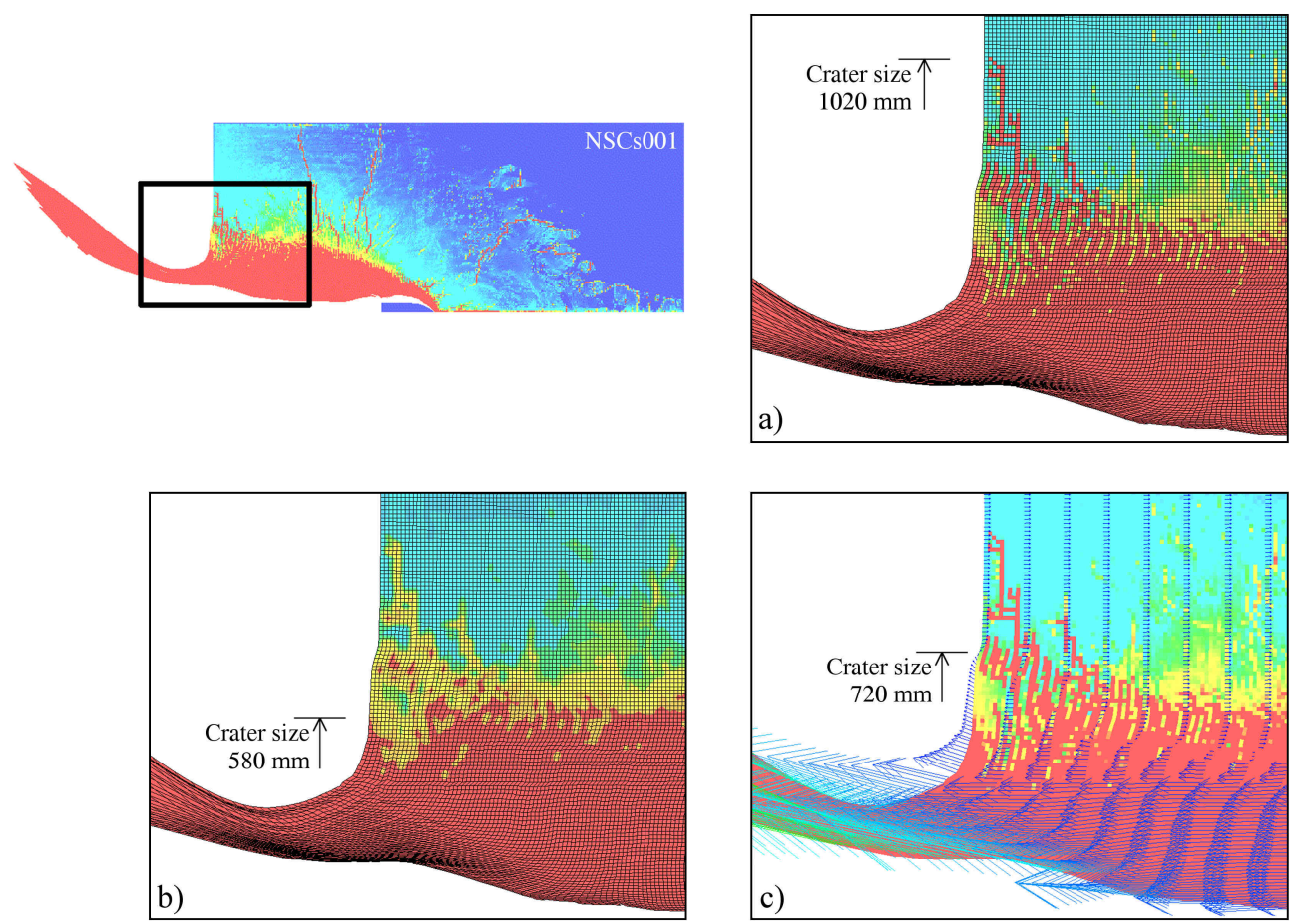
a)

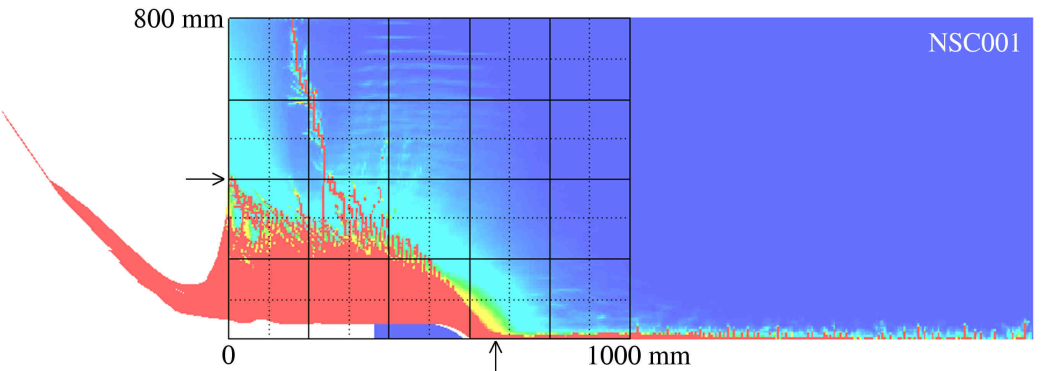

b)

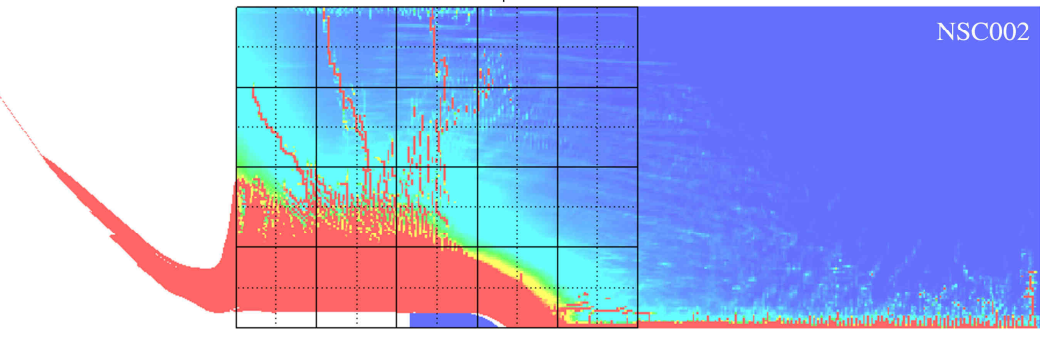

DAMAGE

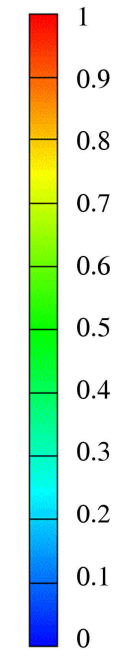

d)

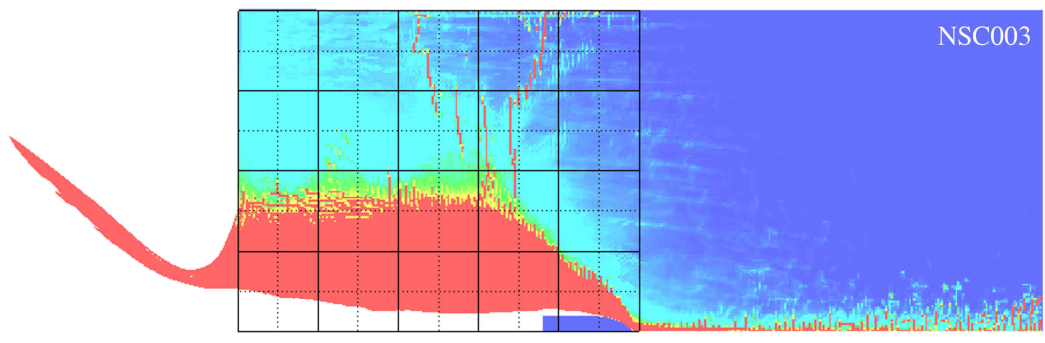

\begin{tabular}{|l}
1 \\
0.9 \\
0.8 \\
0.7 \\
0.6 \\
0.5 \\
0.4 \\
0.3 \\
0.2 \\
0.1 \\
0 \\
\hline
\end{tabular}

c)

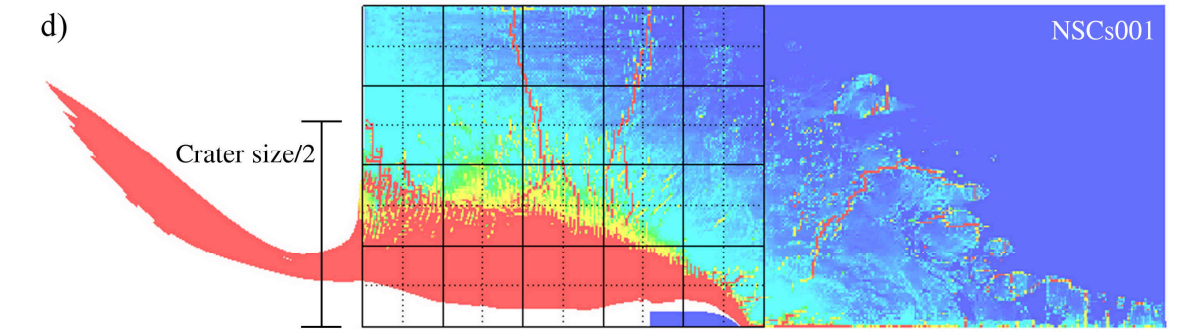



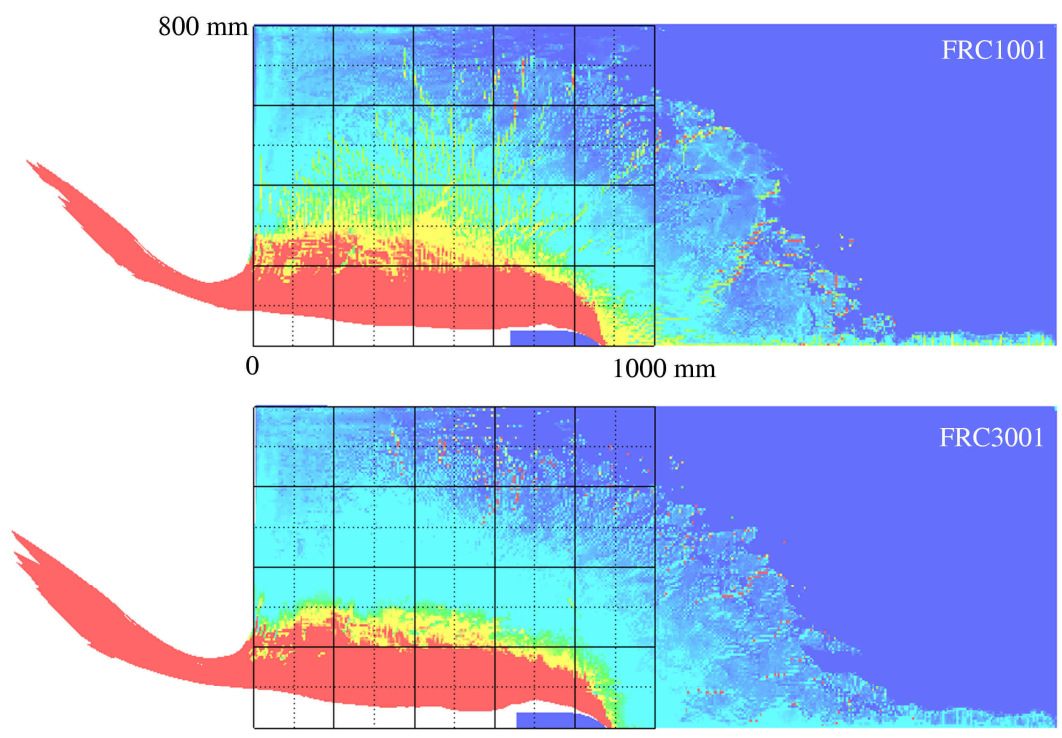

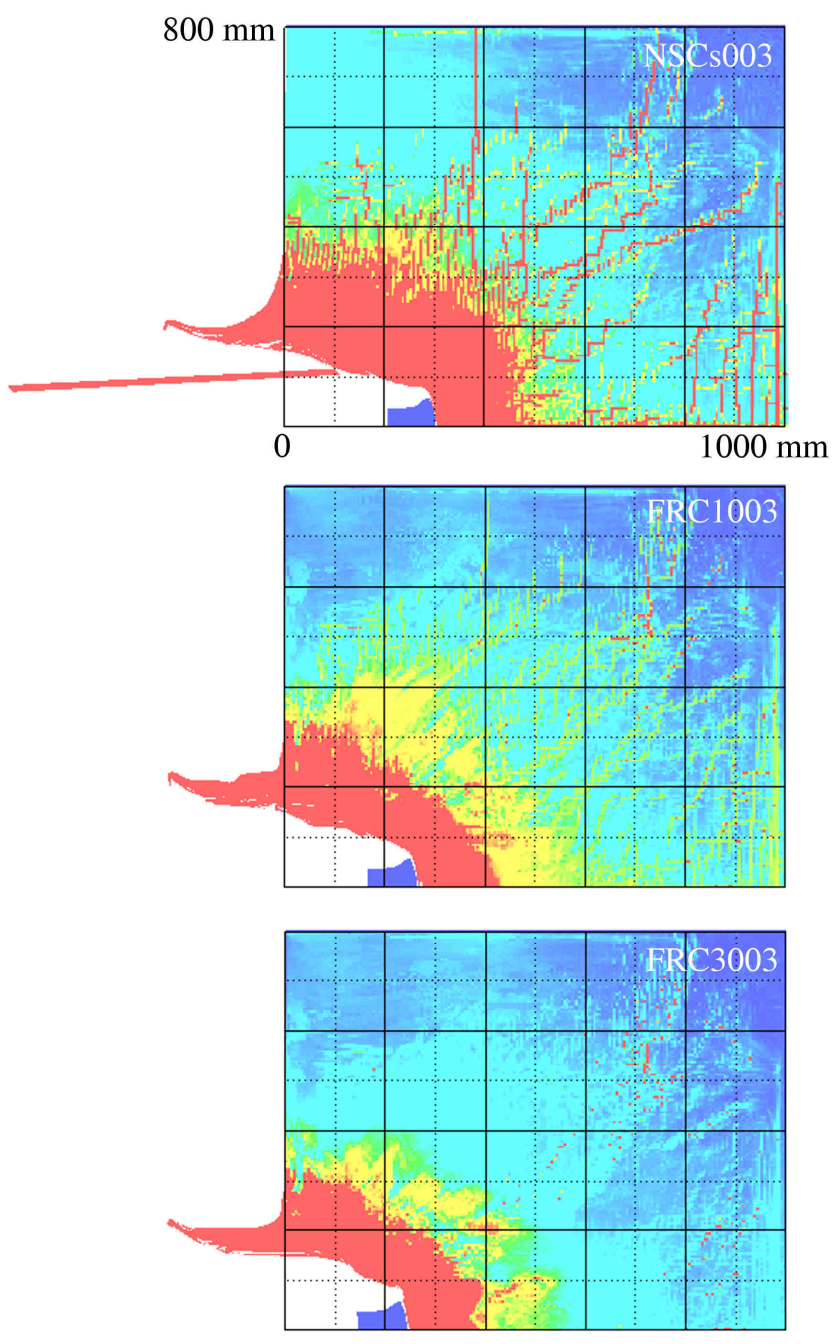